\title{
The London OMED position statement for credentialing and quality assurance in digestive endoscopy
}

Authors

Institutions
D. O. Faigel ${ }^{1}$, P. B. Cotton ${ }^{2}$

Oregon Health and Science University, Portland, Oregon, USA

Medical University of South Carolina, Charleston, South Carolina, USA submitted 27 July 2009 accepted after revision 7 August 2009

\section{Bibliography}

DOI http://dx.doi.org/

10.1055/s-0029-1215279

Published online

6 November 2009

Endoscopy 2009; 41 :

1069-1074 ๑ Georg Thieme

Verlag KG Stuttgart · New York

ISSN 0013-726X

\section{Corresponding author}

\section{O. Faigel, MD}

Division of Gastroenterology and Hepatology

Oregon Health and Science University

3181 SW Sam Jackson Park Rd (L461)

Portland OR 97239-3098

USA

Fax: 01-503-494-7556

faigeld@ohsu.edu
The goal of every clinician (and the health systems in which they work) is to provide high quality medical services. In the case of digestive endoscopy, this means that use of the procedures should adhere to accepted indications, that accurate diagnoses are made, that successful therapies are applied, and that all this is done while maximizing the patient's comfort, and minimizing the risks. The quality assurance process includes granting of privileges only to competent practitioners, ensuring ongoing competence through re-privileging, and engaging in quality improvement through measurement and remediation. Quality is an issue for everyone involved in the endoscopy process, not just the endoscopists.

As a service to the world community, the leadership of OMED (Organisation Mondiale d'Endoscopie Digestive, World Organisation of Digestive Endoscopy) charged Dr. Douglas Faigel and Dr. Peter Cotton to chair a working party of interested endoscopists from a wide range of countries and organizations to develop universal guidelines to assist healthcare institutions in ensuring that the highest quality care be given. The working party met twice, and conducted most of its deliberations by correspondence and conference calls. All known national and international organizations supporting the practice of endoscopy were interrogated for information on relevant topics; many already have extensive publications [1-7]. A list of members of the working party is given in the Appendix.

It is well recognized that resources vary around the world, and that digestive endoscopy is regulated in different ways in different countries (and very little in some), so that the application of these guidelines will vary enormously in extent and method. However, we believe that the recommendations can provide a useful platform from which all systems can move forward. These guidelines should also be used by educational organizations throughout the world to set goals in their continuing medical education programs, thus improving the quality of endoscopy worldwide.

This review does not include discussion of the issues involved in training and credentialing nonphysician endoscopists, which is becoming more common, especially in Britain. However, the same general principles should apply.

\section{Definition of terms, and general principles \\ $\nabla$}

Clinical privilege: Authorization by a local institution for a physician to perform a particular procedure or clinical service. Privileges are granted by healthcare institutions such as hospitals or freestanding surgical or endoscopy centers or clinics. Credentials: Documents provided after successful completion of a period of education or training, as an indication of clinical competence. They include, but are not limited to, diplomas, letters from training directors, and specialty certifications.

Re-credentialing/re-certification/revalidation: Interval assessment and approval of continuing competence to perform specified procedures.

Specificity of privileging: Privileges should be granted separately for each endoscopic procedure: esophagogastroduodenoscopy (EGD), colonoscopy, endoscopic retrograde cholangiopancreatography (ERCP), endoscopic ultrasonography (EUS), enteroscopy and wireless capsule endoscopy. Competency in one procedure does not indicate competency in another procedure, and should not be used for granting privileges in another procedure.

Uniformity of standards: Healthcare institutions must adopt policies for the granting of privileges that apply to all practitioners regardless of specialty and applicable to wherever endoscopy is performed. 
Table 1 Threshold numbers of endoscopic procedures before competency can be assessed by direct observation or other objective measures, as required in different countries or regions.

\begin{tabular}{|c|c|c|c|c|c|c|}
\hline & USA* & Australia $\dagger$ & Canada & Poland & India & Europe $\ddagger$ \\
\hline \multicolumn{7}{|l|}{ Procedure } \\
\hline Sigmoidoscopy & 30 & & 30 & & & 50 \\
\hline Colonoscopy & 140 & 100 to cecum & 150 & 500 & 120 & 150 \\
\hline EGD & 130 & 200 & 150 & 500 & 190 & 200 \\
\hline ERCP & 200 & 200 & 200 & 200 & 140 & 150 \\
\hline EUS & 150 & 200 & & & & 150 \\
\hline
\end{tabular}

EGD, esophagogastroduodenoscopy; ERCP, endoscopic retrograde cholangiopancreatography; EUS, endoscopic ultrasonography

*American Society for Gastrointestinal Endoscopy (ASGE) Guideline

†Colonoscopy: cecal intubation in $>90 \%$ of the last 50 logged procedures. ERCP: unassisted, with intact papilla, to include 80 sphincterotomies and 60 stent placements.

$\ddagger$ European Board of Gastroenterology: colonoscopy numbers include polypectomy, and assume competency in EGD first [10].

\section{Granting privileges \\ $\nabla$}

It is the responsibility of healthcare institutions to grant privileges for endoscopic procedures only to competent individuals. Competency is the minimal level of skill, knowledge, and/or expertise derived through training and experience that is required to safely and proficiently perform a task or procedure, without assistance or supervision [1]. As applied to endoscopy this means that the endoscopist has gone through training to develop requisite skills and acquire the knowledge base needed to safely perform and interpret endoscopic procedures, and to correctly manage the findings from these.

In all cases policies must comply with local, regional, and national guidelines and regulations.

\section{Training requirements}

At the completion of training, the endoscopist must have achieved certain competencies; namely, they must:

- Have successfully completed a sound medical or surgical training

- Be able to integrate endoscopy into the clinical management plan, be this medical, surgical, or referral for specialty services

- Understand the indications, contraindications and risks related to the procedures

- Be able to clearly describe to the patient, in layman's terms, details of the procedure including the attendant risks, and thus to obtain informed consent

- Have knowledge of the endoscopic anatomy

- Be thoroughly familiar with the technical and safety features of the endoscope and accessories, and have an understanding of proper endoscope reprocessing and infection control

- Accurately identify and interpret endoscopic findings

- Understand the pharmacology, administration, and risks of sedation/analgesia

- Be able to perform procedures competently, including common methods for tissue sampling and therapy

- Diagnose complications promptly and competently manage them

- Recognize the limitations of endoscopic technology or of their own skill in the management or therapy of endoscopic findings

- Be able to document findings and communicate them with patients and other healthcare providers

- Be able to maintain a record of key performance indicators.

The framework and environments in which these competencies are learned will vary by country and region.

\section{Determination of competency}

Completion of a standard training program in gastroenterology or general surgery may suggest that the practitioner is ready for independent endoscopic practice, provided that the program included endoscopic training, but competency for specific procedures should be determined by objective measures, wherever possible. Use of simulators may be a useful training adjunct [8] and may have a role in assessing certain technical proficiencies [9], but should not be used in lieu of adequate training and clinical assessment. Documentation of the numbers and types of procedures performed in training is important, and organizations have published "threshold numbers" ( $\bullet$ Table 1$)$.

These numbers are intended to indicate that the trainee may have reached a stage where competency can be assessed by direct observation or other objective measures. Numbers alone should not be used to grant privileges.

It is advisable that specific procedures for determining competency should be established which would specify the role of observers, the number of cases to be observed and the criteria assessed [2,3]. Competency must include proficiency in the common sampling and therapeutic adjuncts to each specific procedure (e.g. polypectomy of polyps smaller than $2 \mathrm{~cm}$ in colonoscopy; ulcer and variceal hemostasis in EGD; removal of stones smaller than $1 \mathrm{~cm}$, or stent insertion in ERCP). It is not acceptable to perform procedures without the ability to safely and effectively address most of the important findings. This statement should not be taken to mean that every endoscopist needs expertise in advanced therapeutic or rarely performed procedures. Nor should it be used as an excuse to carry out therapeutic procedures for which the endoscopist is not thoroughly competent.

Competency in endoscopy (e.g. by nonphysicians) does not imply competence in nonendoscopic management of the conditions encountered, which must be ensured by medical or surgical training in digestive disease. In appropriate circumstances, the patient should be referred for specialty services.

\section{Procedures for granting privileges}

Healthcare institutions are legally responsible for ensuring that those whom they permit to perform procedures are in fact competent [1]. To do so, they must establish specific policies for the granting of privileges. These policies must adhere to principles of uniformity of standards and specificity of privileging, and also comply with local, regional, and national regulations. The policies must apply uniformly to all specialties, wherever endoscopy is performed, and must be determined separately for each endoscopic procedure (EGD, colonoscopy, ERCP, EUS, enteroscopy, capsule endoscopy), to include their therapeutic aspects $[4,5]$. 
The applicant must specify the procedures for which privileges are requested, and provide details of their training in those procedures, and any subsequent experience. The applicant should be free of any physical or mental impairments that would affect endoscopic competency. Their training director should provide documentation of the training the applicant has received for each procedure requested.

The application and credentials should be reviewed by a physician in the healthcare institution who is thoroughly familiar with the procedures in question. This individual may be the medical director of the endoscopy unit and should have privileges to perform at least some of the procedures for which privileges are requested. The medical director then makes recommendations to the privileging board of the healthcare institution as to which procedure privileges should be granted. Difficulties arise when a practitioner seeks privileges for a procedure that is new to the institution. Depending on the complexity of the procedure, it may be wise for the institution to seek outside expert opinion.

Direct observation of the applicant ("proctoring") is desirable and recommended [3]. The observer should be a skilled endoscopist with privileges to perform the procedure being observed. Hospital policy should delineate the role of the observer and specify the number of procedures to be observed and the criteria to be assessed.

These guidelines also apply when established practitioners seek privileges in a new institution. These applicants should provide documentation of their prior procedural volume and case mix, performance data, and letters of recommendation from previous colleagues and supervisors.

\section{Renewal of privileges \\ $\nabla$}

Holding of endoscopic privileges should be time-limited, thus requiring renewal at regular intervals, to ensure the continued competency of the endoscopist [3].

The institution should have a policy which specifies the methods for renewal of privileges, timing (interval between renewals), and a defined approach for dealing with poor performance.

Applications should include supporting evidence, including documentation of an adequate continuing volume of procedures. Institutions may wish to specify a minimum number of procedures. These volume criteria should be separate for each procedure.

Some institutions and health systems will seek additional data, for example regarding:

- Maintenance of specific performance measures

- Participation in quality improvement projects, which may include review of sentinel events (i.e. adverse events and departures from standard of care or hospital policy)

- Continuing medical education in endoscopy (such as attendance at meetings)

- Observation of performance by an assessor.

As with the initial granting of privileges, the application should be reviewed by a physician in the healthcare institution, for instance the medical director of the endoscopy unit, who is thoroughly familiar with the procedures for which privileges are sought. This individual may need to determine whether there have been any complaints about the endoscopist's performance, or other such issues (such as poor behavior), and may seek input from other medical and nonmedical providers.

\section{Quality assurance and improvement}

$\nabla$

The goal of maintaining and enhancing the quality of services should be addressed by a continuous process of measuring aspects of endoscopic performance [6]. Quality improvement involves identification of areas of underperformance through quality measurement, initiation of an improvement plan, and then re-measurement to assess and document improvement.

Each endoscopy unit should have a policy for quality improvement. This begins with a selection of individual indicators with clinical relevance to the particular institution, and may be based on national, regional, or local regulations.

- The policy should specify which of the many possible recommended indicators will be measured, how often, and for how long. Healthcare institutions may choose to measure a subset on a rotating basis. Once performance goals have been reached for a particular indicator, a different subset may be chosen, whilst recognizing the need for periodic reassessment to ensure continued compliance.

- Compliance rates should be specified with the recognition that not all indicators have undergone benchmarking or that benchmarking may not have occurred in every relevant population.

- Poor performance should be addressed, with remedial plans. Underperformers identified by quality measurement should be offered feedback and plans for improvement and retesting.

- Institutional policy should specify the consequences of repeated underperformance, such as loss of clinical privileges.

\section{Sentinel events}

The term "sentinel events" is used to describe significant deviations from optimal patient care. These include departures from hospital policy or accepted standards of care, as well as major procedural adverse events (complications). These can be adverse outcomes of sedation or of the procedure itself, such as cardiopulmonary compromise, bleeding, perforation, or infections or procedure-specific events such as post-ERCP pancreatitis. Examples of departures from hospital policy include inappropriate use of prophylactic antibiotics, inappropriate procedures, lack of written informed consent, inadequate or delayed endoscopy reports, or performance of sedated procedures in unsafe locations within the institution.

Each institution should have policies for the reporting and review of sentinel events, for example through "incident reports". Endoscopy units should keep a log of adverse events and efforts should be made to track delayed events. The increasing use of electronic reporting systems makes this task easier. Events should be reviewed on a regular basis, within the context of continuous quality improvement, in a nonpejorative setting, and preferably with multidisciplinary participation. The goal must be to improve patient care by recognizing and addressing problems as soon as possible.

\section{Quality indicators}

Most flexible endoscopy procedures are low risk, and major complications are rare. This being so, monitoring of adverse events alone is not sufficient to assure ongoing safety or competency. Documentation of the provision of high quality endoscopic services requires measurement of specific end points, called quality metrics, or "indicators" [7]. 
Quality indicators should be clinically relevant, easily measurable, representative of high quality care, correlate with better outcomes, and be evidence-based, wherever possible.

Indicators may be applied to three time periods: pre-procedure (all contacts with the patient until sedation is administered or the endoscope inserted), intraprocedure (until scope removal), and post-procedure (recovery through follow-up including delayed complications). Some indicators are applicable to all procedures, and others only to specific procedures. Indicators vary with regard to the strength of supporting evidence, with some having prospective data, some retrospective, and some representing best clinical practice according to expert opinion.

After review of published quality indicators and taking into account general applicability, ease of measurement, and strength of supporting evidence, the following indicators are recognized as being potentially useful for quality improvement programs:

Generic quality indicators [7]

Indication. In general, endoscopy is indicated when the information gained or the therapy provided will help the patient, and is not indicated when the information or therapy will not have an impact on clinical decision making or outcome. An indication should be documented for each procedure, and when it is a nonstandard indication it should be justified in the documentation. Studies have shown that when EGD and colonoscopy are done for standard indications, more clinically relevant diagnoses are made [11 - 16]. Informed consent. Procedure-specific informed consent that conforms to local, regional and national standards should be obtained and documented in writing. Consent should be obtained and documented for the procedure and any sedation or analgesia provided except in emergency situations with noncompetent patients. The consent should specifically address the reasons for doing the procedure, the possible alternative investigations, what the procedure involves, and the most common complications. Bleeding, perforation, missed diagnosis, and sedation-related complications are common to all endoscopic procedures. Procedure-specific risks (e.g. pancreatitis for ERCP) should be specified. Risk stratification and adverse events. Attention to safety aspects and reporting of adverse events is an important quality measure. Prior to the procedure, the risks are assessed to stratify patients as having a higher or lower risk of complications. Studies using the American Society of Anesthesiologists (ASA) score have demonstrated higher rates of sedation-associated complications in patients undergoing gastrointestinal endoscopy who have higher scores $[17,18]$. The Malampati score, a visual analogue score to assess the upper airway, may also be useful in identifying patients likely to have problems with airway support if needed [18]. Adverse events should be recorded using standard methods, such as those recently developed by the American Society for Gastrointestinal Endoscopy (ASGE) [20].

Reversal agents. Treatment for oversedation with reversal agents (e.g. naloxone, flumazenil) or cessation of propofol should be recorded. Review of the rate at which reversal agents are given or propofol stopped may be a useful surrogate for oversedation and allow identification of unsafe sedation practices. However, use of this indicator should be done carefully and in a nonpenalizing manner lest endoscopists become hesitant to use these lifesaving treatments.

\section{EGD quality indicators [21]}

Biopsy specimens are obtained from gastric ulcers. Unless contraindicated by gastrointestinal bleeding or severe coagulopathy, biopsies should be obtained from gastric ulcers to assess for the presence of an underlying malignancy.

Treatment of ulcer hemorrhage. Patients undergoing EGD for upper gastrointestinal bleeding in whom an ulcer is found with high risk stigmata should be treated with endoscopic therapy, unless contraindicated. High risk stigmata include active bleeding or the identification of a visible vessel. Prospective studies have documented decreased rebleeding rates when endoscopic therapy is applied to these ulcers [22].

Testing of ulcer patients for Helicobacter pylori. Treatment of $H$. pylori infection results in decreased ulcer recurrence rates and complications [23]. Patients with peptic ulcers of the stomach or duodenum should have biopsies to assess for $\mathrm{H}$. pylori, or have in their endoscopy reports plans for subsequent testing. In settings with a very high population prevalence of infection, empirical treatment without $H$. pylori testing of ulcer patients may be justifiable.

Variceal ligation should be favored for endoscopic treatment of esophageal varices, wherever possible [24]. Randomized controlled trials have documented its superiority over sclerotherapy [25]. It is recognized that in economically disadvantaged regions there may be barriers to the adoption of variceal ligation. In these regions, measuring the proportion of patients treated with ligation may be useful as a means of achieving increased adoption of this technique.

\section{Colonoscopy quality indicators [26]}

Colonoscopy surveillance. To avoid both overuse and underuse of surveillance colonoscopy, appropriate surveillance intervals should be applied [27]. These may vary by country, depending on population characteristics and available resources.

Cecal intubation rate. Every colonoscopy report should record depth of insertion of the instrument and whether the cecum was visualized. Cecal intubation should be documented by identification of specific landmarks (appendiceal orifice, cecal strap fold, ileocecal valve) and preferably recorded with photographic evidence. Reasons for an incomplete exam should be documented.

Adenoma detection rate. Colonoscopy is used increasingly to screen asymptomatic average-risk patients. The rate of detection of adenomas (and advanced lesions) is a good measure of quality. In average risk individuals older than 50 years undergoing screening colonoscopy acceptable rates are $\geq 25 \%$ in men and $\geq 15 \%$ in women [26].

Colonoscope withdrawal time. Endoscopists with longer colonoscope withdrawal times have been shown to detect more adenomas and advanced lesions $[28,29]$. The withdrawal time should average $\geq 6$ minutes. Withdrawal time is a surrogate marker for adenoma detection but is useful in quality assurance programs where efforts to increase withdrawal times (such as through using a timer) may increase adenoma detection rates [29].

Quality of colon preparation should be recorded. Studies have shown a higher rate of detection of polyps and adenomas with better preparation $[30,31]$.

\section{ERCP quality indicators [32]}

ERCP cannulation rates. Whether the desired duct (biliary or pancreatic) has been cannulated should be specified. Studies have shown a correlation between procedure volumes during training and ability to selectively cannulate the duct of interest [33]. In expert hands, the desired duct is cannulated in over $90 \%-95 \%$ of cases [34]. 
Post-ERCP pancreatitis rate. Rates of pancreatitis average $1 \%-7 \%$ after ERCP but may be significantly higher in certain clinical settings (and depending on the definitions used) [35].

Biliary stone extraction. Each ERCP report should specify whether biliary stones were extracted and the bile duct cleared. The rate of stone extraction and clearance of the bile duct should be measured [32].

Biliary stent insertion. In patients with distal malignant strictures of the bile duct, the rate of successful stent insertion is recorded. Obstruction of the distal bile duct due to biliary or pancreatic malignancies is a common indication for ERCP. When these malignant strictures are identified, in most cases a biliary stent should be inserted [32].

\section{The endoscopy report}

$\nabla$

The completeness of the endoscopy report is itself a measure of quality. Electronic systems provide an opportunity to make some fields mandatory, or at least to remind those involved about missing data before reports are finalized.

The ASGE recommended the following contents for an endoscopy report [36].

1 Date of procedure

2 Patient identification

3 Endoscopist(s)

4 Assistant(s)

5 Documentation of relevant history and physical examination

6 Documentation of informed consent

7 Endoscopic procedure

8 Indication(s)

9 Endoscopic instrument(s)

10 Medications given

11 Anatomic extent of examination

12 Limitations of examination including quality of preparation

13 Samples obtained

14 Findings

15 Diagnosis/diagnoses

16 Therapy

17 Outcome of therapy

18 Complications

19 Disposition (immediate aftercare, e.g. admission)

20 Recommendations for subsequent care.

\section{Quality improvement in the endoscopy unit \\ $\nabla$}

This report and most others have focused on the competency and performance of the endoscopists. The efficiency, safety, and comfort of a patient's experience rely heavily also on the rest of the team: the manager, nurses, technicians, and other support staff. Thus, measuring the quality of the endoscopy unit and process as a whole is an equally important task. Monitoring efficiency (e.g. wait times, room and staff turnover, no-show rates), allows for the appropriate use and allocation of medical resources [37]. Patient-centered measures such as satisfaction surveys, receipt of written discharge instructions (including instructions as to resumption of meals and medications), post-procedure follow-up, and plans for informing patients of biopsy and laboratory results form the foundation of best clinical practice $[5,38]$.

Units must also provide continuing training and competency assessment of support staff. Important skill areas include but are not limited to: patient monitoring and assessment, medication administration, endoscope set-up and maintenance, use of endoscopic accessories, post-procedure patient recovery, equipment reprocessing, and infection control. Special attention should be paid to reprocessing and infection control. When properly performed, transmission of infection to patients (or staff) should be extremely rare; recent estimates are of fewer than 1/1000000 procedures. Units should have defined policies for reprocessing and infection control that adhere to published multi-society and national and international guidelines $[39,40]$.

In some countries, endoscopy units are inspected and approved by various agencies with different agendas. Eventually it is likely and desirable that units (as well as endoscopists) will be subject to a formal credentialing and re-credentialing process. The ASGE has recently begun to recognizing units committed to high quality standards with their Certificate of Recognition award [41]. The British Global Rating Scale (GRS) for gastrointestinal endoscopy services is an excellent example of the parameters to be used in testing the quality of endoscopy units and their improvement. The GRS is currently used as the standard against which services are assessed in a peer review accreditation process that is aiming to accredit all endoscopic services in the UK [42].

\section{Benchmarking: quality improvement beyond the single endoscopist and unit}

Most of the publications and recommendations have concerned measuring quality (and competency) of single physicians and individual endoscopy units. A broader important agenda is now evolving, i.e. the ability to compare performances across practitioners and units, in other words to "benchmark" performance. Benchmarking entails measuring endoscopist- or unit-specific indicators in a reproducible manner and then comparing those results with those of other endoscopists or units in the database. The purpose is to determine levels of performance and evaluate one's own performance against others. This allows detection of areas of underperformance and rational planning for progress as part of the continuous quality improvement process. Benchmarking also allows local, regional, and national healthcare systems to allocate resources appropriately to achieve quality improvement. International benchmarking would allow individual countries to assess the quality of the endoscopic services they provide.

Benchmarking of endoscopic services is still at a nascent stage. The British GRS, mentioned earlier, has been strikingly successful in this endeavor. Compliance has been close to $100 \%$ and the project has shown progressive and widespread improvements over 4 years [42]. Benchmarking databases for individual endoscopist performance are being developed in several countries. This Working Group strongly supports these efforts. As these tools become available, they should be rapidly adopted by endoscopists, units, and healthcare systems.

\section{Conclusions \\ $\nabla$}

Ensuring the performance of high quality endoscopic procedures is the goal and responsibility of every endoscopist. Quality assurance for endoscopy requires that only competent practitioners be given privileges, that continued competence be demonstrated through a re-privileging process, and that endoscopy units participate in a continuous process of quality improvement. 


\section{Appendix}

$\nabla$

Members of the OMED Working Party

David Armstrong, Canada Thomasz Marek, Poland

Orrin Barrow, Jamaica Amit Maydeo, India

David Bjorkman, USA Jayaram Menon, Malaysia

Ronald Bridges, Canada Ibrahim Mostafa, Egypt

Paul Fockens, Netherlands Enders Ng, China

Rikiya Fujita, Japan Ian Norton, Australia

Khean-Lee Goh, Malaysia Jean-Francois Rey, France

Geir Hoff, Norway Guido Villa-Gomez Roig, Bolivia

Allen Kumar, India Roque Saenz, Chile

Finlay Macrae, Australia Roland Valori, United Kingdom

\section{Competing interests: None}

\section{References}

1 Faigel DO, Baron TH, Lewis B et al. Ensuring competence in endoscopy. ASGE Press, Available at: http://www.asge.org/nspages/practice/patientcare/competence.pdf; Publication date: 2006

2 Barton R. Accrediting competence in colonoscopy: validity and reliability of the UK Joint Advisory Group/NHS Bowel Cancer Screening Programme Accreditation Assessment. Gastrointest Endosc 2008; 67: AB77

3 Dominitiz JA, Ikenberry SA, Andersomn MA et al. Renewal of and proctoring for endoscopic privileges. Gastrointest Endosc 2008; 67: 10-16

4 Eisen GM, Baron TH, Dominitz JA et al. Methods of granting hospital privileges to perform gastrointestinal endoscopy. Gastrointest Endosc 2002; 55: 780-783

5 Armstrong D, Enns R, Ponich $T$ et al. Canadian credentialing guidelines for endoscopic privileges: an overview. Can J Gastroenterol 2007; 21: $797-801$

6 Bjorkman DJ, Popp JW. Measuring the quality of endoscopy. Gastrointest Endosc 2006; 63: S1 -S2

7 Faigel DO, Pike M, Baron TH et al. Quality indicators for endoscopic procedures: an introduction. Gastrointest Endosc 2006; 63: S3 - S9 Am J Gastroenterol 2006; 101: 866-872

8 Cohen J, Cohen SA, Vora KC et al. Multicenter, randomized, controlled trial of virtual-reality simulator training in acquisition of competency in colonoscopy. Gastrointest Endosc 2006; 64: 361 - 368

9 Ritter EM, McCluskey DA, Gallagher AG et al. Perceptual, visuospatial, and psychomotor abilities correlate with duration of training required on a virtual-reality flexible endoscopy simulator. Am J Surg 2006; 192: $379-384$

10 European Board of Gastroenterology. The blue book 2008. Available at: http://www.eubog.org/docs/Blue_Book.pdf; Publication date: 2008

11 Froehlich F, Repond C, Mullhaupt B et al. Is the diagnostic yield of upper GI endoscopy improved by the use of explicit panel-based appropriateness criteria? Gastrointest Endosc 2000; 52: 333-341

12 De Bosset V, Froehlich F, Rey JP et al. Do explicit appropriateness criteria enhance the diagnostic yield of colonoscopy? Endoscopy 2002; 34: $360-368$

13 Balaguer F, Llach J, Castells A et al. The European panel on the appropriateness of gastrointestinal endoscopy guidelines colonoscopy in an open-access endoscopy unit: a prospective study. Aliment Pharmacol Ther 2005; 21: 609-613

14 Morini S, Hassan C, Meucci G et al. Diagnostic yield of open access colonoscopy according to appropriateness. Gastrointest Endosc 2001; 54 : $175-179$

15 Bersani G, Rossi A, Ricci G et al. Do ASGE guidelines for the appropriate use of colonoscopy enhance the probability of finding relevant pathologies in an open access service? Dig Liver Dis 2005; 37: 609-614

16 Charles RJ, Chak A, Cooper GS et al. Use of open access in GI endoscopy at an academic medical center. Gastrointest Endosc 1999; 50: 480485

17 Vargo JJ, Holub JL, Faigel DO et al. Risk factors for cardiopulmonary events during propofol-mediated upper endoscopy and colonoscopy. Aliment Pharmacol Ther 2006; 24: 955-963

18 Sharma VK, Nguyen CC, Crowell MD et al. A national study of cardiopulmonary unplanned events after GI endoscopy. Gastrointest Endosc 2007; 66: $27-34$
19 Langeron O, Masso E, Huraux C et al. Prediction of difficult mask ventilation. Anesthesiology 2000; 92: 1229-1236

20 Cotton PB, Eisen G, Vargo J et al. A lexicon for adverse events; report of an ASGE workshop. Gastrointest Endosc 2009; In press:

21 Cohen J, Safdi MA, Deal SE et al. Quality indicators for esophagogastroduodenoscopy. Gastrointest Endosc 2006; 63: S10-S15 Am J Gastroenterol 2006; 101: 886-891

22 Adler DG, Leighton JA, Davila RE et al. ASGE guideline: The role of endoscopy in acute non-variceal upper-GI hemorrhage. Gastrointest Endosc 2004; 60: $497-504$

23 Ford A, Delaney B, Forman $D$ et al. Eradication therapy for peptic ulcer disease in Helicobacter pylori positive patients. Cochrane Database Syst Rev 2004; 18: CD003840

24 Eisen GM, Baron TH, Dominitz JA et al. The role of endoscopic therapy in the management of variceal hemorrhage. Gastrointest Endosc 2002; 56: $618-620$

25 Villanueva C, Colomo A, Aracil C, Guarner C. Current endoscopic therapy of variceal bleeding. Best Pract Res Clin Gastroenterol 2008; 22: 261 278

26 Rex DK, Petrini JL, Baron TH et al. Quality indicators for colonoscopy. Gastrointest Endosc 2006; 63: S16- S28 Am J Gastroenterol 2006; 101: $873-885$

27 Rex DK, Bond JH, Winawer S et al. Quality in the technical performance of colonoscopy and the continuous quality improvement process for colonoscopy: recommendations of the U.S. Multi-Society Task Force on Colorectal Cancer. Am J Gastroenterol 2002; 97: 1296-1308

28 Barclay RL, Vicari JJ, Doughty AS et al. Colonoscopic withdrawal times and adenoma detection during screening colonoscopy. N Engl J Med 2006; 355: $2533-2541$

29 Barclay RL, Vicari JJ, Greenlaw RL. Effect of a time-dependent colonoscopic withdrawal protocol on adenoma detection during screening colonoscopy. Clin Gastroenterol Hepatol 2008; 6: 1091 - 1098

30 Harewood GC, Sharma VK, de Garmo P. Impact of colonoscopy preparation quality on detection of suspected colonic neoplasia. Gastrointest Endosc 2003; 58: 76- 79

31 Froelich F, Wietlisbach V, Gonvers JJ et al. Impact of colonic cleansing on quality and diagnostic yield of colonoscopy: the European Panel of Appropriateness of Gastrointestinal Endoscopy European Multicenter Study. Gastrointest Endosc 2005; 61: $378-384$

32 Baron TH, Petersen BT, Mergener $K$ et al. Quality indicators for endoscopic retrograde cholangiopancreatography. Gastrointest Endosc 2006; 63: S29-S34 Am J Gastroenterol 2006; 101: 892 - 897

33 Jowell PS. Quantitative assessment of procedural competence: A prospective study of training in ERCP. Ann Intern Med 1996; 125: $937-$ 939

34 Schlup MM, Williams SM, Barbezat GO. ERCP: a review of technical competency and workload in a small unit. Gastrointest Endosc 1997; 46: $48-52$

35 Freeman ML, Guda NM. Prevention of post-ERCP pancreatitis: a comprehensive review. Gastrointest Endosc 2004; 59: 845 - 864

36 American Society for Gastrointestinal Endoscopy.. Quality improvement of gastrointestinal endoscopy. Gastrointest Endosc 1999; 49: $842-$ 844. Available at: http://www.asge.org/WorkArea/showcontent.aspx? id = 3388; Publication date: 1999

37 Brotman M, Allen JI, Bickston SJ et al. AGA Task Force on Quality in Practice: a national overview and implications for GI practice. Gastroenterology 2005; 129: 361 - 369

38 Johanson JF, Schmitt CM, Deas TM et al. Quality and outcomes assessment in gastrointestinal endoscopy. Gastrointest Endosc 2000; 52: $827-830$

39 Multi-society guidelines for reprocessing flexible gastrointestinal endoscopes. Gastrointest Endosc 2003; 58: 1- 8. Available at: http:// www.asge.org/WorkArea/showcontent.aspx?id = 3376; Publication date: 2003

40 World Gastroenterology Organisation-OMGE and Organisation Mondiale d'Endoscopie Digestif (OMED). WGO-OMGE and OMED practice guideline: Endoscope disinfection. Available at: http://www.omed. org/downloads/pdf/guidelines/wgo_omed_endoscope_disinfection. pdf; Publication date: Dec 142005

41 American Society for Gastrointestinal Endoscopy. ASGE Endoscopy Unit Recognition Program. http://www.asge.org/ITTIndex.aspx?id = 6254; Publication date: 2009

42 Joint Advisory Group on Gastrointestinal Endoscopy (JAG). The Global Rating Scale. http://www.grs.nhs.uk/; Publication date: 2009 